\title{
Prepubertal tamoxifen treatment affects development of heifer reproductive tissues and related signaling pathways
}

\author{
A. Al Naib, ${ }^{*}$ H. L. M. Tucker,† G. Xie, ${ }^{*}$ D. H. Keisler, $\ddagger$ F. F. Bartol,§ R. P. Rhoads, ${ }^{*}$ R. M. Akers, $\dagger$ \\ and M. L. Rhoads*1 \\ *Department of Animal and Poultry Sciences, and \\ †Department of Dairy Science, Virginia Polytechnic Institute and State University, Blacksburg 24061 \\ ‡Division of Animal Sciences, University of Missouri, Columbia 65211 \\ §Department of Anatomy, Physiology and Pharmacology, Cellular and Molecular Biosciences Program, Auburn University, Auburn, AL 36849
}

\begin{abstract}
Prepubertal exposure of the developing ovaries and reproductive tract (RT) to estrogen or xenoestrogens can have acute and long-term consequences that compromise the reproductive performance of cattle. This research examined effects of the selective estrogen receptor modulator tamoxifen (TAM) on gene and protein abundance in prepubertal ovaries and RT, with a particular focus on signaling pathways that affect morphology. Tamoxifen was administered to Holstein heifer calves $(\mathrm{n}=8)$ daily $(0.3 \mathrm{mg} / \mathrm{kg}$ subcutaneously) from 28 to $120 \mathrm{~d}$ of age, when tissues were collected. Control calves $(\mathrm{n}=7)$ received an equal volume of excipient. Weight, gross measurements, and samples of reproductive tissues were collected, and protein and mRNA were extracted from snap-frozen samples of vagina, cervix, uterus, oviduct, ovary, and liver. Neither estradiol nor insulin-like growth factor I (IGFI) concentrations in the serum were affected by TAM treatment. Tamoxifen treatment reduced ovarian weight independently from effects on antral follicle populations, as there was no difference in visible antral follicle numbers on the day of collection. Estrogen receptor $\alpha(E S R 1)$ and $\beta$ (ESR2) mRNA, ESR1 protein, IGFI, progesterone receptor, total growth hormone receptor, WNT4, WNT5A, and WNTYA mRNA, in addition to mitogenactivated protein kinase (MAPK) and phosphorylated MAPK proteins were affected differently depending on the tissue examined. However, neither IGFI receptor mRNA nor protein abundance were affected by TAM treatment. Results indicate that reproductive development in prepubertal Holstein heifer calves is TAMsensitive, and that bovine RT and ovarian development are supported, in part, by estrogen receptor-dependent
\end{abstract}

Received November 24, 2015.

Accepted March 2, 2016.

${ }^{1}$ Corresponding author: rhoadsm@vt.edu mechanisms during the period studied here. Potential long-term consequences of such developmental disruption remain to be defined.

Key words: estrogen, uterus, ovary, prepubertal

\section{INTRODUCTION}

Globally, reproductive performance of high-producing dairy cows is poor (Leroy et al., 2015). Considerable efforts have been expended to identify factors responsible for this multifactorial dilemma (Walsh et al., 2011). In this regard, little attention has focused on ovarian or reproductive tract (RT) development during the prepubertal period, a time when heifers experience marked growth and development of the entire reproductive tract (Honaramooz et al., 2004). To the extent that disruption of prepubertal RT development can have lasting and often negative effects on reproductive performance (Bartol et al., 2006; Cooke et al., 2013), it is important to identify factors that affect organizationally critical postnatal developmental events.

The developmental program that ultimately defines the functional capacity of female RT tissues is sensitive to steroid hormone receptor modulating compounds (Bartol et al., 1999, 2006; Cooke et al., 2013). Selective estrogen receptor (ER) modulators (SERM), which may act differentially as ER agonists or antagonists, can disrupt RT development with lasting and often negative consequences, especially when encountered during critical organizational periods of pre- or perinatal life (Bartol et al., 1995, 1999, 2006). The risk of exposure to compounds with potential to disrupt steroid hormone-sensitive RT programming events is real. As reviewed elsewhere (Bartol et al., 2006), sources of such compounds can include pharmaceuticals designed for therapeutic purposes, bioactive dietary factors found in feedstuffs (such as subterranean clover, soybeans, legumes, and silage contaminated with mycoestrogens), and industrial chemicals that act as hormonal mimics or endocrine disruptors (McLachlan et al., 2012). Any 
interference with RT development has the potential to result in long-term reductions in fertility.

Calves can be exposed to estrogenic compounds that contaminate their environment and drinking water (Hilton and Thomas, 2003; Ashton et al., 2004; Fent et al., 2006). For example, in the UK, the pharmaceutical tamoxifen (TAM) was detected in sewage effluents, where concentrations ranged between 146 and $369 \mathrm{ng} / \mathrm{L}$ (Roberts and Thomas, 2006). Furthermore, TAM is not degraded in the sewage treatment process and has been found in estuarine waters at concentrations ranging from 27 to 212 ng/L (Thomas and Hilton, 2004; Fent et al., 2006; Roberts and Thomas, 2006).

Tamoxifen, a SERM (Mueller and Korach, 2001), can act as either an ER agonist or an antagonist depending on species, tissue, and dosage (Vallet et al., 1995; Hoffmann, 2000). Like estradiol, SERM can signal through canonical genomic and nongenomic pathways (Banerjee et al., 2014; Kiyama and Wada-Kiyama, 2015). The canonical mechanism is well documented in a wide range of cells (Shupnik, 2004; Hewitt et al., 2005; Yu et al., 2012). Nongenomic mechanisms are less well understood but could provide an explanation for tissue-specific SERM effects (Frasor et al., 2003, 2004; Banerjee et al., 2014). Nongenomic signaling mechanisms are complex, as they involve interactions between numerous signaling pathways, including mitogen-activated protein kinase (MAPK) and the WNT/B-catenin systems. Furthermore, cellular responses to estrogens and SERM can also be influenced by synergistic interactions with other hormones such as IGF-1. For example, in previous studies, a bidirectional interaction between estrogen receptor $\alpha$ (ESR1) and the IGFI receptor (IGFIR) signaling pathways was reported (Milewicz et al., 2005; Yu et al., 2012) at different molecular levels in multiple cell models (Shupnik, 2004; Lanzino et al., 2008; Yu et al., 2012).

Tight control of WNT/B-catenin signaling is required for the initiation, development, and normal function of the female RT (Spencer et al., 2012; van der Horst et al., 2012). The WNT family of genes encodes a group of 19 secreted signaling molecules that regulate cellcell interactions, cell fate, differentiation, and growth (Polakis, 2000). Prenatal and postnatal exposure to endocrine disruptors results in WNT signaling alteration and disruption of the Müllerian duct development (Sassoon, 1999; Kitajewski and Sassoon, 2000; Spencer et al., 2005; Bartol et al., 2006). Within the WNT family, WNT4, WNT5A, and WNT7A are the most extensively studied molecules in the developing RT, specifically examined in sheep and mice. Null mutants of WNT4 and WNT5A fail to form Müllerian ducts (Vainio et al., 1999; Yamaguchi et al., 1999), and WNT7A-null mutants are viable but exhibit malformations in the RT, including the lack of endometrial glands, hypoplastic uterine horns, shortened and uncoiled oviducts, and a vaginal septum (Miller and Sassoon, 1998; Bartol et al., 2006; Spencer et al., 2012).

The previously mentioned molecules and pathways are involved in reproductive processes, and are also potential targets for endocrine-based disruption of development. Evaluating effects of targeted exposure of developing female reproductive tissues to steroid hormones and related steroid receptor modulators, including estrogens and related SERM, constitutes a strategy for identification of steroid hormone-sensitive organizational processes and molecular markers of normal and disrupted development (Cooke et al., 2013). In this regard, comparatively little is known about ER-dependent, estrogen- or SERM-sensitive events associated with organization and programming of RT or ovarian development in cattle. This study was designed to identify effects of TAM on RT and ovarian development at morphological and molecular levels in prepubertal Holstein heifer calves.

\section{MATERIALS AND METHODS}

\section{Animals}

The protocols for this experiment were reviewed and approved by the Institutional Animal Care and Use Committee at Virginia Tech (Blacksburg). Holstein heifer calves $(\mathrm{n}=15$; initial BW of $49.5 \pm 1.0 \mathrm{~kg})$ were purchased from a commercial dairy farm at 2 wk of age and transported to the Virginia Tech Dairy Center. Calves were housed individually in calf hutches until weaning at 8 wk of age and then group housed through the completion of the study. Calves were fed milk replacer (Land O'Lakes Cow's Match Cold Front, Land O'Lakes, Arden Hills, MN) at the recommended rate twice daily until weaning, after which they received only pelleted grain and hay. Every 2 wk, calves were weighed and hip height measurements were taken.

\section{Experimental Protocol}

Upon arrival at the Virginia Tech Dairy Center, calves were randomly assigned to control $(\mathrm{n}=7)$ or treatment $(\mathrm{n}=8)$ groups (TAM; tamoxifen citrate, TCI America, Portland, OR). Beginning at $28 \mathrm{~d}$ of age, TAM was administered subcutaneously at a rate of 0.3 $\mathrm{mg} / \mathrm{kg}$ of BW per day. The carrier for TAM injections was composed of $30 \%$ ethanol, $30 \%$ benzyl benzoate, and $40 \%$ corn oil. Control animals were given an equal volume of carrier. Treatment dosages were adjusted every 2 wk when BW were taken. Because tamoxifen has not previously been administered to calves of this 
age, it was uncertain at what dose, if any, effects on the reproductive tract would be observed. Therefore, the dose administered was based upon the amount given to human breast cancer patients (Jager et al., 2014).

\section{Tissue and Blood Collection}

Before the calves were euthanized on postnatal d 120, blood was collected by jugular venipuncture into untreated evacuated glass tubes (BD Vacutainer, Franklin Lakes, NJ) and transported to the laboratory. Serum was collected following centrifugation at $2,500 \times g$ for $20 \mathrm{~min}$ and then frozen at $-20^{\circ} \mathrm{C}$. Heifers $(120 \pm 0.3 \mathrm{~d}$ of age) were killed using a phenobarbital solution administered intravenously (Euthasol, $10 \mathrm{mg} / \mathrm{kg}$ of BW; Butler Schein Animal Health Supply, Dublin, $\mathrm{OH}$ ) and then exsanguinated. Reproductive tissues were removed and evaluated immediately. Total RT weight, including the cervix, uterus, oviducts, and ovaries (trimmed free of connective tissues), as well as the weight of each ovary was recorded for each calf. Follicles visible on the surface of each ovary were counted. Cross-sections of the vagina, cervix, uterus, oviduct, and ovaries were collected along with a portion of the liver. Tissues were snap frozen in liquid nitrogen and stored at $-80^{\circ} \mathrm{C}$ until RNA and protein extraction.

\section{RNA Isolation and cDNA Synthesis}

Total RNA was isolated from each tissue type using Isol-RNA Lysis Reagent (Fisher, Pittsburgh, PA). Purification of RNA and DNase treatment was conducted with the RNeasy Mini Kit (Qiagen, Valencia, CA). The RNA concentration was calculated using the absorbance at $260 \mathrm{~nm}$ measured with a nanophotometer (Implen, Westlake Village, CA). Initially, quality of the RNA was evaluated using the $260 / 280 \mathrm{~nm}$ ratio, and then was further evaluated with the Experion Automated Electrophoresis System analysis (BioRad, Hercules, CA). The RNA was then stored at $-80^{\circ} \mathrm{C}$ until cDNA was synthesized from $1 \mu \mathrm{g}$ of RNA using an iScript cDNA Synthesis Kit (BioRad). The cDNA was stored at $-20^{\circ} \mathrm{C}$.

\section{Real-Time Quantitative Reverse Transcription-PCR}

Real-time quantitative reverse transcription (RT)PCR was used to measure the abundance of several genes in the reproductive tract and liver. Reactions were performed in duplicate in $20-\mu \mathrm{L}$ volumes using SsoAdvanced SYBR Green Supermix (BioRad) and the CFX96 Real-Time System (BioRad). For each gene, 40 PCR cycles were run and a melt curve was assessed to verify a single amplified PCR product. The abundance of each gene was calculated based on comparison with a 6-point standard curve that was made using 10-fold dilutions of plasmid DNA $\left(3 \times 10^{6}, 3 \times 10^{5}, 3 \times 10^{4}, 3\right.$ $\times 10^{3}, 3 \times 10^{2}$, and $3 \times 10^{1}$ copies). Each PCR product was cloned using a TA Cloning Kit (Invitrogen, Grand Island, NY) and transformed into One Shot Mach1 T1 phage-resistant chemically competent Escherichia coli (Invitrogen). Plasmid DNA was extracted using a QIAprep Spin Miniprep Kit (Qiagen). Concentration and purity were determined via nanophotometer (Implen). The amplicon was then submitted to the Virginia Bioinformatics Institute (Blacksburg) for sequencing. Standard curves as well as a negative control and no template control were run on each real-time RT-PCR plate. Primers are given in Table 1.

\section{Western Blotting}

About $50 \mathrm{mg}$ (wet tissue weight) of each tissue type was powdered, resuspended, and homogenized in lysis buffer $(10 \mathrm{~m} M$ Tris-HCl, $1 \mathrm{~m} M$ EGTA, $150 \mathrm{~m} M \mathrm{NaCl}$, and $1 \%$ Triton X-100) supplemented with protease and phosphatase inhibitors (Halt protease and phosphatase inhibitor cocktail, Thermo-Scientific, Rockford, IL) using tissue lyser (Thermo-Scientific, Waltham, MA). Whole-tissue lysates were centrifuged at $13,000 \times g$ for $15 \mathrm{~min}$ at $4^{\circ} \mathrm{C}$. The resulting supernatants were collected and protein concentrations were measured using a bicinchoninic acid kit (Thermo-Scientific, Rockford, IL). Proteins were denatured by boiling for $5 \mathrm{~min}$ at $95^{\circ} \mathrm{C}$ in loading buffer (NuPAGE LDS Sample Buffer $4 \times$, Invitrogen) supplemented with 5\% mercaptoethanol. Equal amounts of sample protein were subjected to SDS-PAGE (Laemmli, 1970) using a 10\% (total monomer) gel. Proteins were transferred to a nitrocellulose membrane, which was blocked with blocking buffer [5\% BSA in a Tris-buffered saline-Tween-20 (TBST) containing $10 \mathrm{~m} M$ Trizma base, $100 \mathrm{~m} M \mathrm{NaCl}$, and $0.5 \%$ Tween-20] for $1 \mathrm{~h}$ at room temperature. Immunoblotting was performed by incubating the membranes in blocking buffer overnight at $4^{\circ} \mathrm{C}$ with primary antibodies of rabbit polyclonal anti-IGFIR $\beta$ (1:1,000; Cell Signaling, Danvers, MA), rabbit polyclonal anti-ESR1 (1:1,000; Santa Cruz Biotechnology Inc., Santa Cruz, CA), rabbit polyclonal anti-MAPKp44/42 (1:1,000; Cell Signaling), rabbit polyclonal anti-phospho-MAPKp44/42 (1:2000; Cell Signaling), and rabbit polyclonal anti- $\beta$ actin (1:1,000; Cell Signaling). Measurement of $\beta$-actin was used as a loading control. Bands were visualized with IRDye fluorescent secondary antibodies (Li-Cor Biosciences, Lincoln, NE) and quantified using Li-Cor Biosciences Odyssey imaging system and software. 
TAMOXIFEN AFFECTS BOVINE REPRODUCTIVE TISSUES

\section{Hormone Analyses}

Serum estradiol concentrations were previously measured (Tucker et al., 2016) by validated RIA (Velayudhan et al., 2015). Assay sensitivity was $0.079 \mathrm{pg} / \mathrm{mL}$ and the intra- and interassay coefficients of variation were 15.2 and $16.0 \%$, respectively. Serum IGFI concentrations were measured by validated RIA as described in Rhoads et al. (2008), with minimum detectability of $0.13 \mathrm{ng} / \mathrm{mL}$ and an intraassay coefficient of variation of $13.0 \%$.

\section{Statistical Analyses}

Reproductive tract weight was calculated by subtracting the weight of both ovaries from the combined weight of the cervix, uterus, oviducts, and ovaries. The vagina was not included in the analysis of weight because the amount of vagina collected from each heifer was inconsistent. One tamoxifen-treated heifer was excluded from molecular analyses due to poor quality or yield of mRNA and protein. Before statistical analysis of each variable, outliers were identified using the Grubbs outlier evaluation method and then excluded. Data were checked for normality and homogeneity of variance using histograms, qqplots, and formal statistical tests in the Univariate procedure (version 9.1.3; SAS Institute Inc., Cary, NC). Data that were not normally distributed were transformed where appropriate. Variables were analyzed for an effect of treatment using the mixed models procedure of SAS. Heifer nested within treatment was included in the model as a random effect. Gene abundance data are reported as copy number. Results are reported as least squares means \pm SEM. Where transformations were necessary, the means are presented after back-transformation as least squares means \pm SEM.

\section{RESULTS}

\section{Morphology of the Reproductive Tissues}

Treating calves with TAM disrupted multiple aspects of reproductive development. On the day of slaughter, the wet weight of the RT with ovaries was reduced by almost one-third in the TAM group (Figure 1; $P<$ 0.01). This reduction in weight was also apparent when evaluated as a percentage of BW (Figure $1 ; P<0.01$ ). The reduction in RT weight following TAM treatment was due to a decrease in ovarian weight (Figure $1 ; P$ $<0.01$ ) as well as a numerical decrease in the weight of other RT tissues (cervix, uterus, and oviduct). The ovaries of TAM-treated animals were less than half the weight of those of the control group. The reduction in 

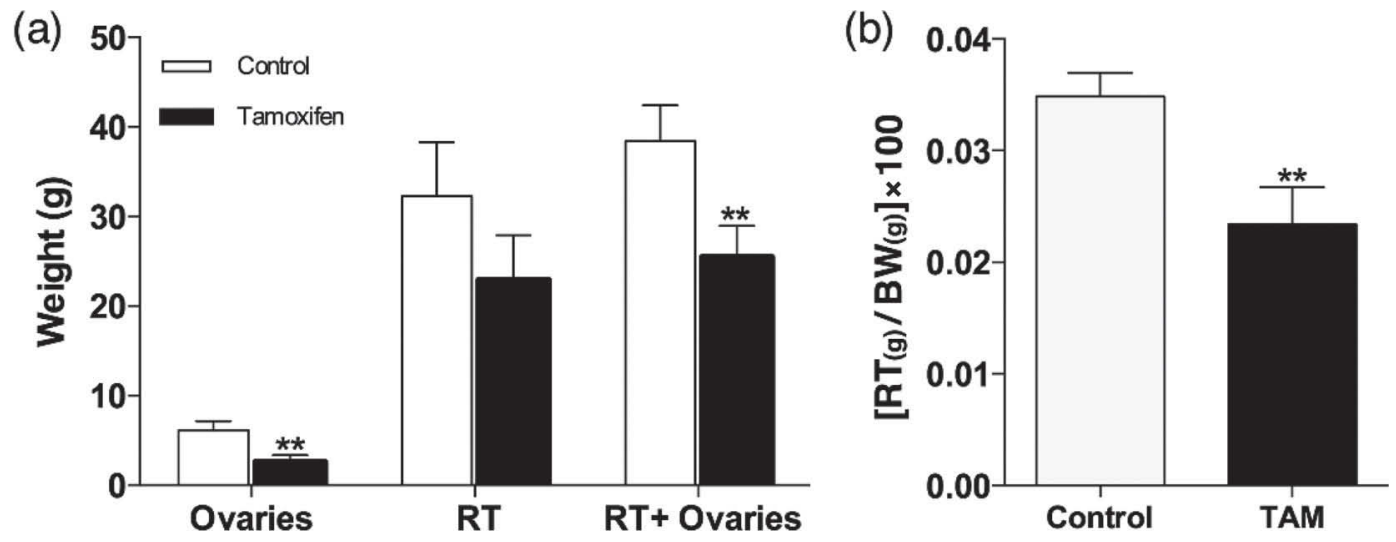

Figure 1. (a) Weights of the ovaries, reproductive tract (RT; including cervix, uterus, and oviducts), and the combined weight of the ovaries and RT of tamoxifen (TAM)-treated and control groups; (b) reproductive tissue weights as percentage of whole BW. Data are shown as least squares means $\pm \mathrm{SEM} ;{ }^{* *} P<0.01$.

ovarian weight following TAM treatment was not related to the antral follicle population, as antral follicle numbers on the day of slaughter did not differ between groups $(35.9 \pm 6.0$ vs. $36.8 \pm 6.5$ for TAM and control, respectively; $P>0.10)$.

\section{Serum Estradiol and IGFI Concentrations}

Serum estradiol concentrations were previously reported and were not affected by TAM treatment (Tucker et al., 2016). Similarly, IGFI concentrations did not differ between TAM-treated and control heifers on the day of slaughter $(106.2 \pm 14.7$ vs. $105.7 \pm 14.7 \mathrm{ng} /$ $\mathrm{mL}$ for TAM and control, respectively; $P>0.10$ ).

\section{Estrogen Signaling Pathway}

Animals treated with TAM displayed a reduction in both ESR 1 mRNA (Figure 2; $P<0.05$ ) and protein in most RT tissues that were examined, including the vagina (Figure $3 ; P<0.01$ ), cervix (Figure $4 ; P<$ 0.01 ), uterus (Figure 5; $P<0.01$ ), and oviduct (Figure $6 ; P<0.05)$. This reduction was most apparent in the cervix and uterus, where there was more than an $80 \%$ reduction in ESR1 protein. Treatment with TAM also decreased ESR $1 \mathrm{mRNA}$ abundance in the liver (Figure 2; $P<0.10$ ). Abundance of ESR2 mRNA (Figure 2) was decreased in the uterus $(P<0.01)$ and the oviduct $(P<0.10)$ in the TAM-treated group. In contrast, ESR2 transcript abundance in the vagina was greater following TAM treatment $(P<0.01)$.

\section{IGFI/MAPK Signaling Pathway}

Tamoxifen treatment increased IGFI mRNA abundance (Figure 2$)$ in the cervix $(P<0.01)$, uterus $(P$
$<0.01)$, oviduct $(P<0.01)$, and vagina $(P<0.10)$. The abundance of IGFIR mRNA (Figure 2) and protein (Figures 3 to 8 ) did not differ between treatment groups in any of the tissues examined. Heifers treated with TAM displayed increased total MAPK protein in the vagina (Figure $3 ; P<0.05$ ), oviduct (Figure $6 ; P<$ 0.05 ), ovary (Figure $7 ; P<0.05$ ), and liver (Figure $8 ; P$ $<0.05)$, but reduced total MAPK protein in the uterus (Figure 5; $P<0.05$ ). Tamoxifen treatment increased the phosphorylated form of the MAPK protein in the ovary (Figure $7 ; P<0.05$ ), but decreased phosphorylated MAPK in the cervix (Figure $4 ; P<0.10$ ).

\section{WNT Abundance}

Tamoxifen treatment reduced WNT7A transcript abundance in the uterus 22 -fold $(P<0.01)$ and decreased $W N T 7 A$ mRNA in the cervix and oviduct (Figure $2 ; P<0.05)$. Similarly, WNT5A mRNA abundance was reduced in the uterus of TAM-treated heifers $(P<$ 0.01). Conversely, TAM treatment increased WNT5A transcript abundance in the oviduct (Figure 2; $P<$ 0.05 ). Abundance of WNT4 mRNA was higher in the vagina $(P<0.01)$ and oviduct $(P<0.05)$ following TAM treatment but lower in the uterus (Figure 2; $P$ $<0.10)$.

\section{Progesterone Receptor and Total Growth Hormone Receptor}

Unlike the ER, TAM treatment increased abundance of the progesterone receptor $(P R)$ transcript in the vagina, cervix, uterus, and oviduct (Figure 2; $P<0.01$ ). Progesterone receptor mRNA abundance in the ovary remained unchanged. Similarly, total growth hormone receptor (TGHR) mRNA (Figure 2) increased following 


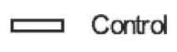

Tamoxifen
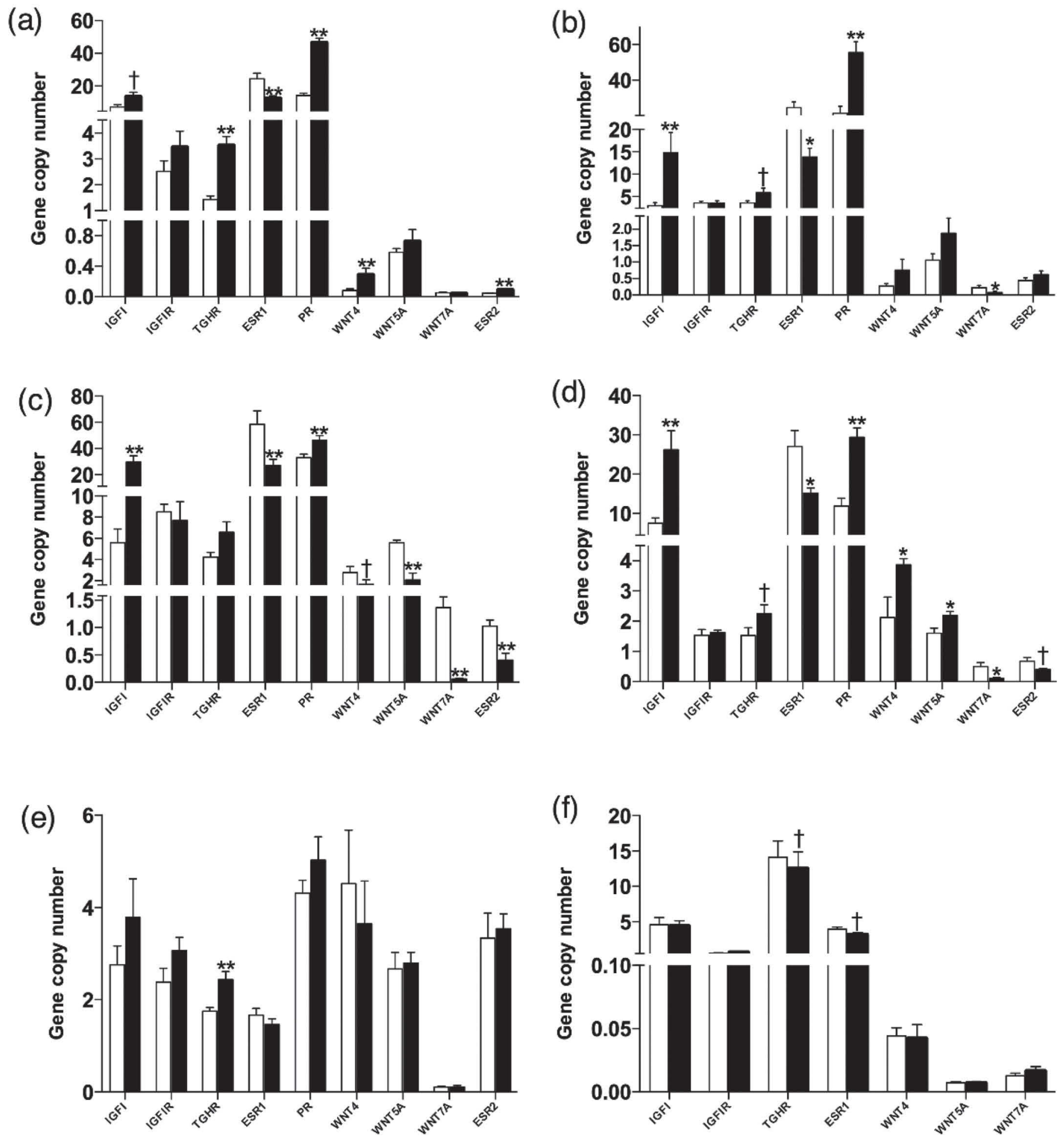

Figure 2. Gene copy number of insulin-like growth factor I (IGFI), IGFI receptor (IGFIR), total growth hormone receptor ( $T G H R)$, estrogen receptor $\alpha(E S R 1)$, progesterone receptor $(P R), W N T 4, W N T 5 A, W N T 7 A$, and estrogen receptor $\beta$ (ESR2) in vagina (a), cervix (b), uterus (c), oviduct (d), ovary (e), and liver (f) of tamoxifen and control groups, as determined by real-time quantitative PCR. Values are expressed as least squares means $\pm \mathrm{SEM} ;{ }^{* *} P<0.01,{ }^{*} P<0.05$, and $\dagger P<0.10$. 

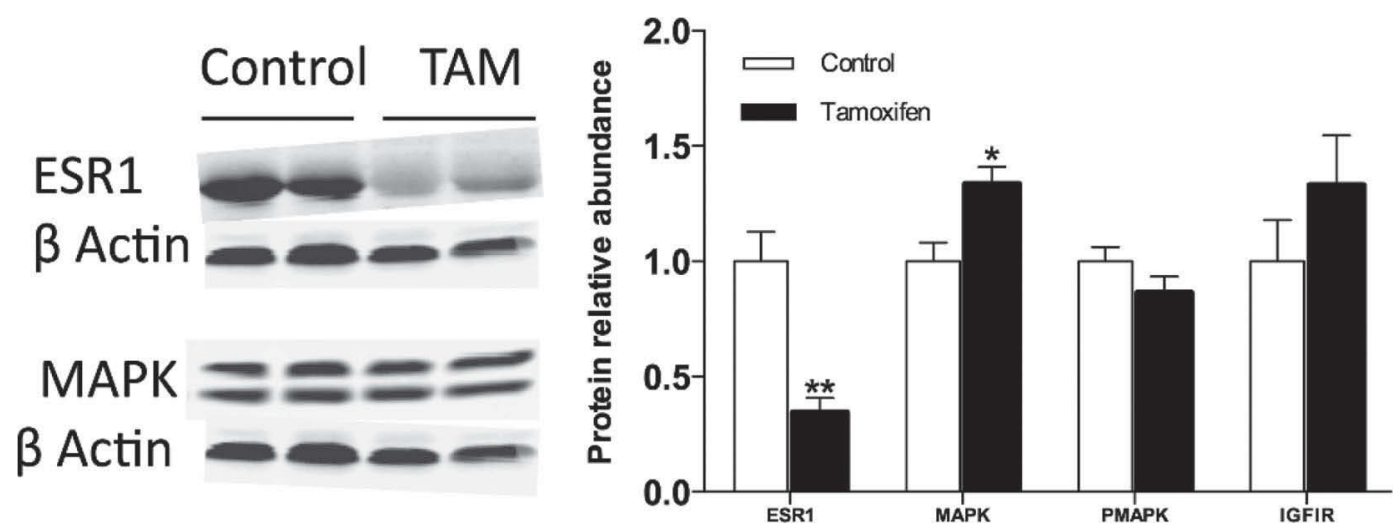

Figure 3. Western immunoblotting of estrogen receptor $\alpha$ (ESR1; $65 \mathrm{kDa}$ ), mitogen-activated protein kinase (MAPK; 42 and $44 \mathrm{kDa})$, phosphorylated MAPK (PMAPK; 42 and $44 \mathrm{kDa}$ ), and insulin-like growth factor I receptor (IGFIR; $95 \mathrm{kDa}$ ) in vagina of tamoxifen-treated (TAM) and control groups. Blot insert (left) shows staining intensity from 2 representative control heifers and 2 representative TAM heifers. Data are presented as mean relative abundance to control $\pm \mathrm{SEM} ;{ }^{* *} P<0.01$ and ${ }^{*} P<0.05$.

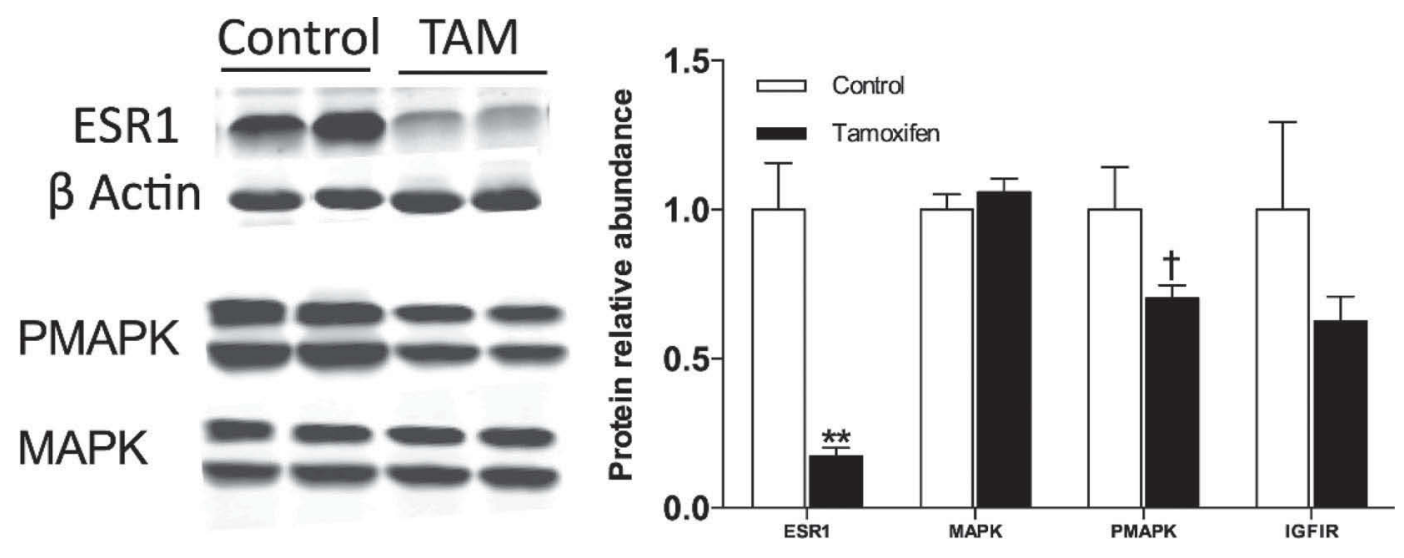

Figure 4. Western immunoblotting of estrogen receptor $\alpha$ (ESR1; $65 \mathrm{kDa})$, mitogen-activated protein kinase (MAPK; 42 and $44 \mathrm{kDa})$, phosphorylated MAPK (PMAPK; 42 and $44 \mathrm{kDa}$ ), and insulin-like growth factor I receptor (IGFIR; $95 \mathrm{kDa}$ ) in cervix of tamoxifen-treated (TAM) and control groups. Blot insert (left) shows staining intensity from 2 representative control heifers and 2 representative TAM heifers. Data are presented as a mean relative abundance to control \pm SEM; $* * P<0.01$ and $\dagger P<0.10$.
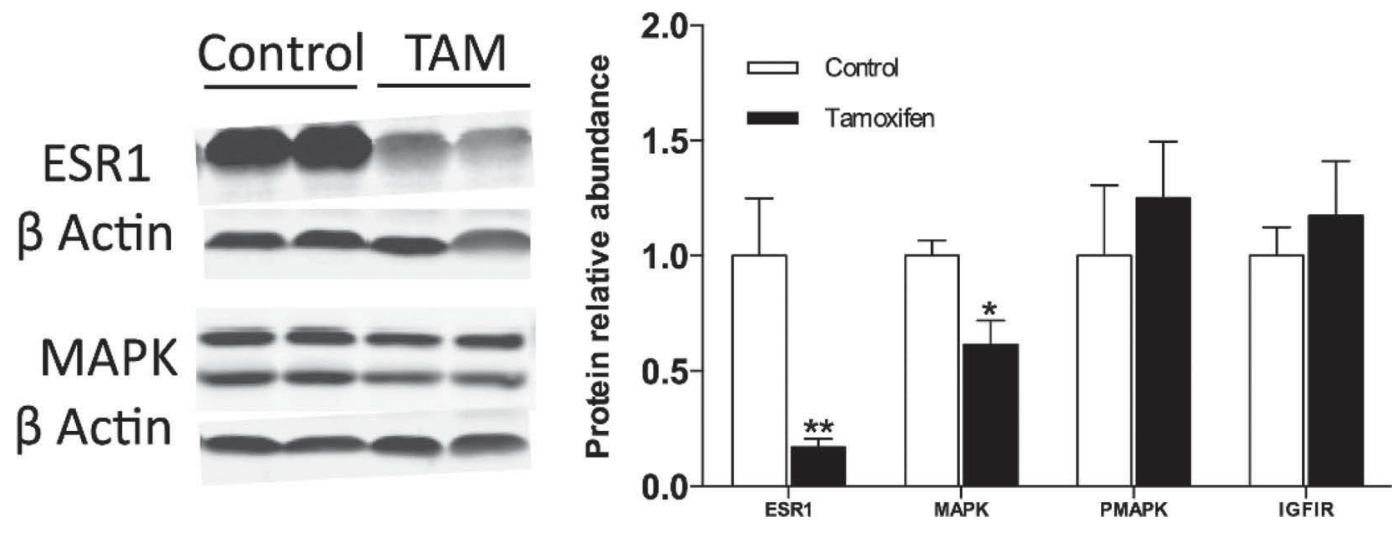

Figure 5. Western immunoblotting of estrogen receptor $\alpha$ (ESR1; $65 \mathrm{kDa})$, mitogen-activated protein kinase (MAPK; 42 and $44 \mathrm{kDa})$, phosphorylated MAPK (PMAPK; 42 and $44 \mathrm{kDa}$ ), and insulin-like growth factor I receptor (IGFIR; $95 \mathrm{kDa}$ ) in the uterus of tamoxifen-treated (TAM) and control groups. Blot insert (left) shows staining intensity from 2 representative control heifers and 2 representative TAM heifers. Data are presented as a mean relative abundance to control $\pm \mathrm{SEM} ;{ }^{* *} P<0.01$ and ${ }^{*} P<0.05$. 

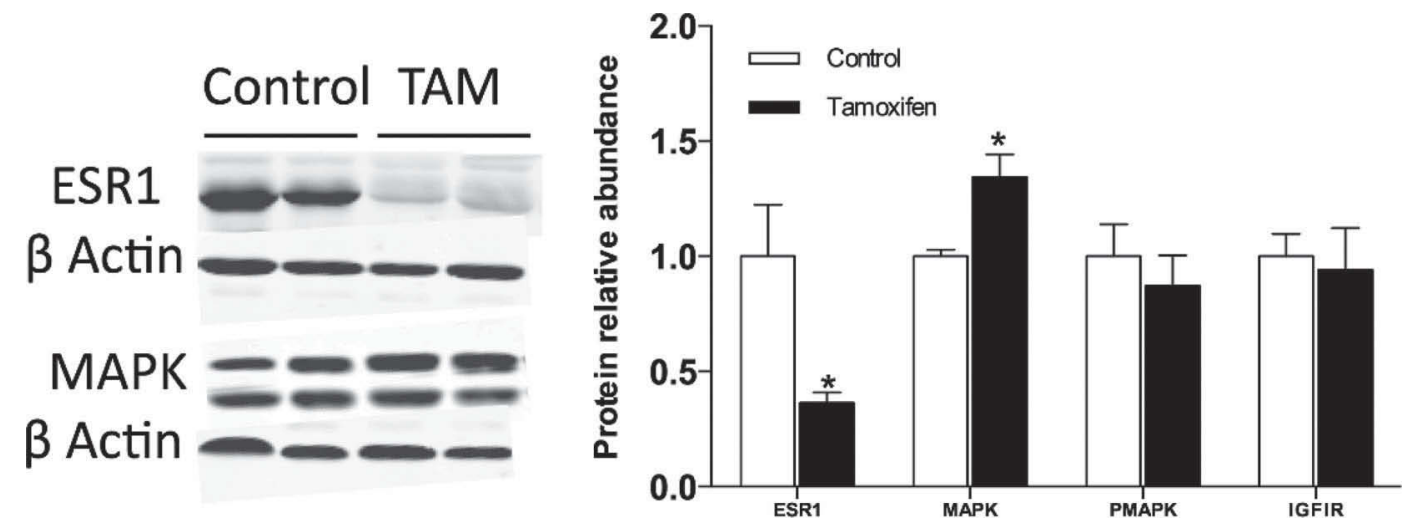

Figure 6. Western immunoblotting of estrogen receptor $\alpha$ (ESR1; $65 \mathrm{kDa}$ ), mitogen-activated protein kinase (MAPK: 42 and $44 \mathrm{kDa})$, phosphorylated MAPK (PMAPK; 42 and $44 \mathrm{kDa}$ ), and insulin-like growth factor I receptor (IGFIR; $95 \mathrm{kDa}$ ) in oviduct of tamoxifen-treated (TAM) and control groups. Blot insert (left) shows staining intensity from 2 representative control heifers and 2 representative TAM heifers. Data are presented as a mean relative abundance to control $\pm \mathrm{SEM} ;{ }^{*} P<0.05$.
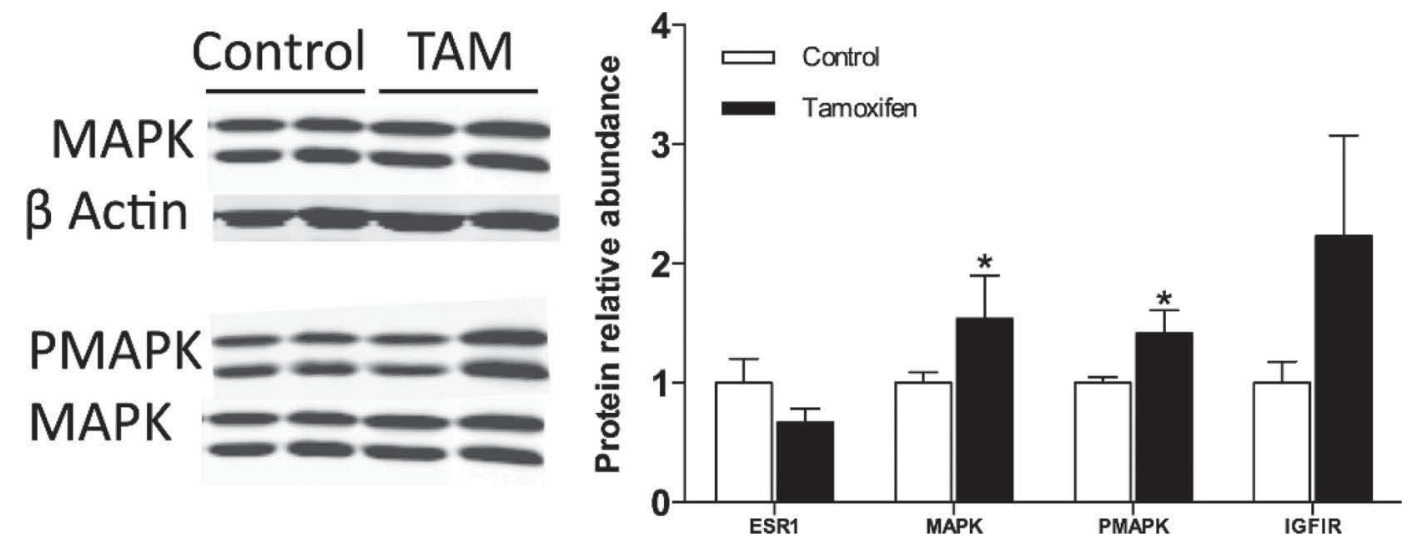

Figure 7. Western immunoblotting of estrogen receptor $\alpha$ (ESR1; $65 \mathrm{kDa})$, mitogen-activated protein kinase (MAPK; 42 and $44 \mathrm{kDa})$, phosphorylated MAPK (PMAPK; 42 and $44 \mathrm{kDa}$ ), and insulin-like growth factor I receptor (IGFIR; $95 \mathrm{kDa}$ ) in ovary of tamoxifen-treated (TAM) and control groups. Blot insert (left) shows staining intensity from 2 representative control heifers and 2 representative TAM heifers. Data are presented as a mean relative abundance to control $\pm \mathrm{SEM} ;{ }^{*} P<0.05$.
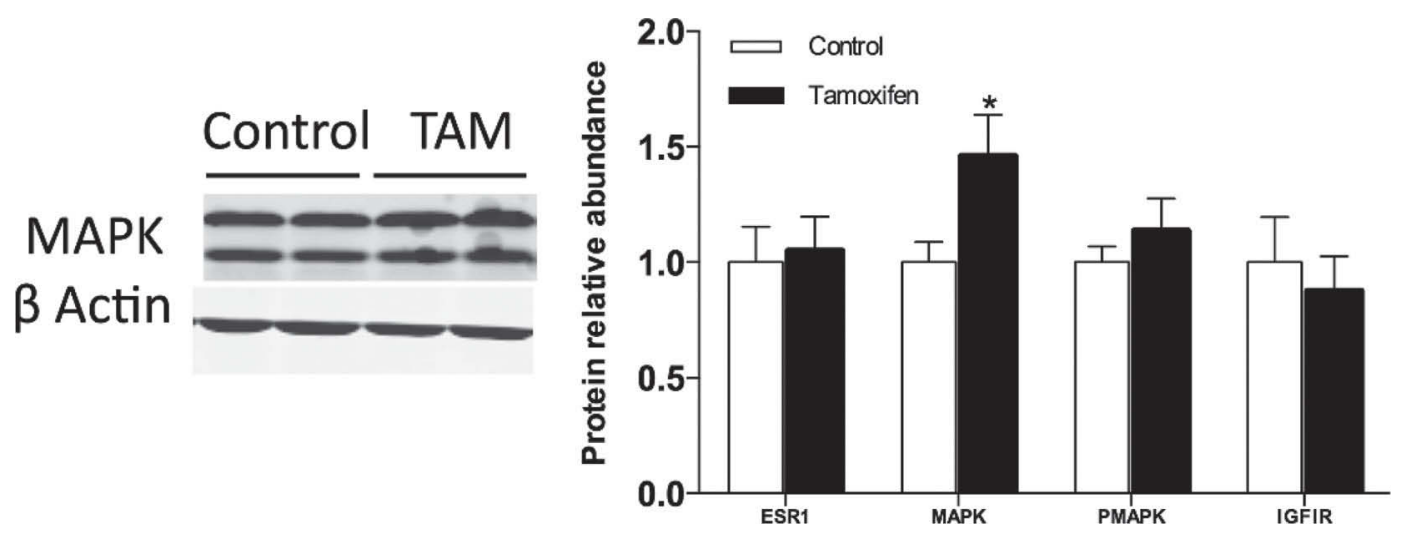

Figure 8. Western immunoblotting of estrogen receptor $\alpha$ (ESR1; $65 \mathrm{kDa})$, mitogen-activated protein kinase (MAPK; 42 and $44 \mathrm{kDa})$, phosphorylated MAPK (PMAPK; 42 and $44 \mathrm{kDa}$ ), and insulin-like growth factor I receptor (IGFIR; $95 \mathrm{kDa}$ ) in liver of tamoxifen-treated (TAM) and control groups. Blot insert (left) shows staining intensity from 2 representative control heifers and 2 representative TAM heifers. Data are presented as a mean relative abundance to control $\pm \mathrm{SEM} ;{ }^{*} P<0.05$. 
TAM treatment in the vagina $(P<0.01)$, ovary $(P<$ $0.01)$, cervix $(P<0.10)$, and oviduct $(P<0.10)$.

\section{DISCUSSION}

Structure, function, and competency of the reproductive tissues are essential for fertility, and abnormalities in the ovaries and RT are likely to cause subfertility or infertility (Spencer et al., 2012). Bovine reproductive tissues are vulnerable to insult during early postnatal life (Bartol et al., 1995). During this time, the potential for exposure to environmental chemicals, including endocrine-disrupting compounds, is a growing concern (Fowler et al., 2012). However, this has received relatively little attention in cattle. Although the amount of tamoxifen administered during this experiment was higher than environmental contamination levels (27 to $369 \mathrm{ng} / \mathrm{L}$; Thomas and Hilton, 2004; Fent et al., 2006; Roberts and Thomas, 2006), results of this study demonstrate that development of the bovine reproductive tract is affected by changes in estrogen signaling. The main finding of the current work was that the endocrine disruptor TAM altered patterns of ovarian and RT development in prepubertal Holstein calves. These effects were manifested as changes in the gross anatomy of the ovaries and RT, as well as in changes in the abundance of molecules associated with signaling pathways involved in reproductive tissue development (Spencer et al., 2012; van der Horst et al., 2012).

The age at which the heifers were treated with TAM (4 to 17 wk of age) coincides with a time of rapid RT development. Honaramooz and coworkers (2004) showed that ovarian dimensions of heifers increase rapidly from 2 to 14 wk of age, and diameters of the vagina, cervix, and uterine body increase from 2 to at least $20 \mathrm{wk}$ of age. Herein, we report that the total wet weight of the reproductive tissues of TAM-treated heifers was less than that of control heifers. This reduction was observed when the weight of the reproductive tissues (RT + ovaries) was evaluated as an absolute value and when it was evaluated as a percentage of BW, indicating that this difference was independent of $\mathrm{BW}$ and not simply a result of treatment-induced differences in isometric growth.

The lack of treatment effect on the weight of the RT alone was somewhat surprising because TAM was administered during a period of marked RT growth (Honaramooz et al., 2004). The uterus accounts for the largest proportion of tissue in the RT, and its development is far more complex than changes in weight and dimensions. Postnatal uterine development includes development of endometrial folds, emergence and proliferation of endometrial glands, growth of endometrial caruncular areas, and growth of the myometrium (Wiley et al., 1987; Bartol et al., 1988; Taylor et al., 2000). Although the results of the current experiment suggest that TAM treatment did not affect uterine growth, measurements obtained here do not indicate whether the histoarchitecture of the uterus was altered by TAM treatment.

For the current experiment, even though the weight of the ovaries was reduced in response to TAM treatment, the number of visible antral follicles did not differ between treatment groups. Therefore, the reduction in ovarian weight was likely due to changes in other component(s) of the ovary. Previous experiments indicate that the population of preantral follicles as well as characteristics of the stroma can be affected by TAM treatment. When administered prenatally, TAM treatment reduced follicular development and stromal cell density in the ovaries of neonatal mice (Roshangar et al., 2010). Exposure to estrogen mimics is also known to affect ovarian development in several species. Neonatal exposure to bisphenol A (postnatal d 1 to 14) decreased the weight of the ovaries of lambs at $30 \mathrm{~d}$ of age. Similar to our results, even though ovarian weight decreased in bisphenol A-exposed lambs, no differences in the total number of follicles were reported (Rivera et al., 2011). Exposure of neonatal mice to genistein, the most abundant dietary phytoestrogen, at environmentally relevant doses altered ovarian differentiation and development, and resulted in subfertility or infertility in adulthood (Jefferson et al., 2002, 2005). Although the subsequent fertility of TAM-treated heifers was not evaluated in the current study, results of these previous experiments demonstrate that exposure to estrogenic compounds can have long-term effects on reproduction.

To be able to draw conclusions about the activity of TAM in the current experiment, it was important to verify that circulating estradiol concentrations did not differ between control and treated animals. Because circulating estradiol concentrations were not affected, changes in the reproductive tissues recorded here can be attributed to direct effects of TAM, rather than a secondary effect of altered serum estradiol concentrations. As previously discussed, TAM is a SERM and can therefore act as an ER agonist or antagonist in a tissue-specific manner. Chemically, TAM is very similar to estrogen and can bind to the same site on the ER as the natural ligand. Some reports using cell lines transfected with an estrogen response element-based reporter showed that TAM was a pure antagonist of ER (Hall and McDonnell, 1999). However, this is not necessarily the case in the uterus, where TAM generally acts as an ER agonist (Klotz et al., 2000; Webb et al., 2003; Wu et al., 2005). 
Classification of TAM as strictly an ER agonist or antagonist in a particular tissue is difficult and has long been a matter of debate in rat uterus, for example (Ferguson and Katzenellenbogen, 1977; Branham et al., 1985). When administered to piglets on postnatal d 1 to 14, TAM affected uterine development in a manner similar to treatment with estradiol (Vallet et al., 1995). These results indicate that TAM was acting as an estrogen agonist in uterine tissue of pigs. Because the objectives of the current experiment did not necessitate inclusion of an estradiol-treated group, it was not possible to definitively determine the mode of action of TAM (i.e., agonistic or antagonistic).

Despite being unable to determine the mode of action of TAM (agonistic or antagonistic), TAM treatment appeared to alter tissue sensitivity to estradiol as indicated by changes in ER populations. In all reproductive tissues except the ovary, ESR1 mRNA and protein abundance was reduced by TAM. Ovarian concentrations of ESR1 did not differ between control and TAM-treated heifers even though the ovaries were the reproductive tissue affected most severely by TAM treatment.

Changes in the abundance of ESR2 mRNA followed a pattern similar to that of ESR1 in the cranial portion of the reproductive tissues. Abundance of ESR2 mRNA did not differ in the ovary but was reduced in the oviduct and uterus. In the vagina, however, ESR2 transcript abundance increased following TAM treatment. Overall, the abundance of ESR2 mRNA in the vagina was considerably lower than in other RT tissues. The biological significance of increased ESR2 mRNA is unknown. The $\alpha$ and $\beta$ isoforms of ER are not functionally equivalent and they play distinct roles in ER action in vitro and in vivo (Mueller et al., 2004). Furthermore, receptor response to circulating hormone concentrations varies with physiological status. Little is known about the distinct roles of ESR1 and ESR2 during RT development in cattle. In mice, homozygous ESR2 nulls have no defects in RT differentiation or fertility, suggesting that the $\beta$ isoform of the receptor has little or no involvement in RT development (Krege et al., 1998). Conversely, ESR1 is essential for normal peripubertal uterine growth and development (Lubahn et al., 1993) and co-localizes with proliferating cell nuclear antigen (PCNA) in ovarian granulosa cells (Saji et al., 2000). Thus, the observed reduction in reproductive tissue weight, and especially the reduction in ovarian weight may be a reflection of ESR1 disruption associated with compromised proliferation in the reproductive tissues of TAM-treated animals.

Estrogen receptor- $\alpha$ is phosphorylated at serine 118 in the presence of estradiol and by growth factor peptides acting through their receptors. This results in activation of the MAPK (ERK 1/2) pathway, which can lead to transcription, as shown both in vitro and in vivo (Denton et al., 1992; Chen et al., 2002). Activation of ESR1 by growth factors such as IGFI involves direct serine phosphorylation via MAPK pathways (IgnarTrowbridge et al., 1996). When activated, (phosphorylated) MAPK accumulates in the nucleus; it plays a prominent role in the regulation of cellular proliferation and cell cycle progression (Swartz et al., 2005). Evidence from uterine leiomyoma cells suggests that activation of the estrogen-mediated MAPK pathway requires the presence of the IGFIR because silencing the IGFIR diminishes effects induced by estradiol (Yu et al., 2012). The TAM treatment administered during the current experiment did not affect hepatic IGFI mRNA concentrations, circulating IGFI concentrations, or mRNA or protein abundance of IGFIR. Despite an apparent lack of effect on these components of the IGFI system, total and phosphorylated MAPK were affected by TAM treatment in all tissues examined. Total MAPK was higher in the vagina and oviduct but lower in the uterus of TAM-treated heifers. Phosphorylated MAPK did not differ in any of these tissues (vagina, oviduct, and uterus) but tended to be lower in the cervices of the TAM group. The abundance of ESR1 (mRNA and protein) was also lower in these tissues following TAM treatment. These findings suggest that the nonovarian RT tissues were comparably less responsive to the TAM treatment, and agree with the morphological data indicating no treatment effects on RT weight.

Ovarian tissue was the only tissue in which both total and phosphorylated MAPK was affected by TAM (increased in both). This agreed with observed changes in ovarian weight and ESR1 abundance. These results provide further evidence that the ovaries are responsive to TAM treatment, and that observed effects on ovarian development might be mediated through the ER.

In addition to TAM-mediated effects resulting from interaction with the ER, the IGFI system directly affects development of bovine reproductive tissues. In many organ systems, including the uterus, IGFI regulates cell proliferation, differentiation, and function via autocrine or paracrine mechanisms (Giudice, 1994; Nayak and Giudice, 2003). Involvement of the IGFI system in postnatal uterine growth and morphogenesis was demonstrated in sheep and rodents (Baker et al., 1996; Gu et al., 1999; Taylor et al., 2001). In most tissues examined during the present study, TAM treatment increased TGHR and IGFI mRNA abundance. These findings appear contradictory because even though IGFI is known to promote growth, the ovaries and RT of the TAM-treated heifers weighed less. Oth- 
ers reported similar results, finding that TAM induced endometrial IGFI mRNA abundance (Roy et al., 2000). The significance of the locally produced IGFI was not apparent from the results of this study.

Tamoxifen treatment tended to reduce hepatic abundance of TGHR mRNA but did not affect hepatic IGFI mRNA abundance or circulating IGFI concentrations. Conversely, previous research in breast cancer patients showed that TAM treatment suppressed hepatic IGFI secretion (Pollak et al., 1992). This discrepancy is likely due to differences in species or physiological state, as the reduction in IGFI in the human studies was thought to result from a reduction in pituitary growth hormone secretion. Although growth hormone was not measured in the current study, the lack of difference in IGFI suggests that growth hormone concentrations were not limiting.

Three ligands from the WNT gene family were measured in tissues collected during this experiment; WNT signaling plays a major role in early development of various organs, including the RT (Spencer et al., 2012). Tamoxifen treatment reduced uterine mRNA abundance of WNT5A and WNTrA and tended to reduce abundance of $W N T 4$. The abundance of $W N T r A$ mRNA was also reduced in the oviduct and cervix. These results are similar to previous reports in mice, where WNT4, WNT5A, and WNT7A were suppressed during diethylstilbestrol-induced disruption of postnatal uterine development. This disruption was mediated by ESR1 (Couse et al., 2001). Results of additional experiments indicate that WNT5A and WNT7A act in conjunction to control uterine gland formation (Mericskay et al., 2004). The concomitant reduction in WNT5A and $W N T Y A$ transcripts within the uterine tissue of the TAM-treated heifers in the current study suggests that uterine gland formation could be affected. Interestingly, TAM treatment increased WNT4 mRNA abundance in the vagina and oviduct as well as WNT5A mRNA abundance in the oviduct. Mericskay and coworkers (2004) proposed that, in postnatal mice, WNT5A regulates the downregulation of WNT7A. This agrees with changes observed in the RT of TAM-treated heifers.

\section{CONCLUSIONS}

Prepubertal exposure to the endocrine disruptor TAM affects the reproductive tissues of Holstein calves. Although all reproductive tissues were affected by TAM treatment to some degree, effects on the ovary were most pronounced. Any and all of the described changes have the potential to compromise the integrity of the reproductive tissues and hence future fertility. However, the long-term effect on reproductive performance requires further investigation.

\section{ACKNOWLEDGMENTS}

Funding for this work was provided, in part, by the Virginia Agricultural Experiment Station (Blacksburg) and the Hatch Program of the National Institute of Food and Agriculture, US Department of Agriculture (Washington, DC).

\section{REFERENCES}

Ashton, D., M. Hilton, and K. V. Thomas. 2004. Investigating the environmental transport of human pharmaceuticals to streams in the United Kingdom. Sci. Total Environ. 333:167-184.

Baker, J., M. P. Hardy, J. Zhou, C. Bondy, F. Lupu, A. R. Bellve, and A. Efstratiadis. 1996. Effects of an Igf1 gene null mutation on mouse reproduction. Mol. Endocrinol. 10:903-918.

Banerjee, S., K. L. Chambliss, C. Mineo, and P. W. Shaul. 2014. Recent insights into non-nuclear actions of estrogen receptor alpha. Steroids 81:64-69.

Bartol, F. F., L. L. Johnson, J. G. Floyd, A. A. Wiley, T. E. Spencer, D. F. Buxton, and D. A. Coleman. 1995. Neonatal exposure to progesterone and estradiol alters uterine morphology and luminal protein content in adult beef heifers. Theriogenology 43:835-844.

Bartol, F. F., A. A. Wiley, and C. A. Bagnell. 2006. Uterine development and endometrial programming. Soc. Reprod. Fertil. Suppl. 62:113-130.

Bartol, F. F., A. A. Wiley, J. G. Floyd, T. L. Ott, F. W. Bazer, C. A. Gray, and T. E. Spencer. 1999. Uterine differentiation as a foundation for subsequent fertility. J. Reprod. Fertil. Suppl. 54:287-302.

Bartol, F. F., A. A. Wiley, and D. R. Goodlett. 1988. Ovine uterine morphogenesis: Histochemical aspects of endometrial development in the fetus and neonate. J. Anim. Sci. 66:1303-1313.

Branham, W. S., D. M. Sheehan, D. R. Zehr, K. L. Medlock, C. J. Nelson, and E. Ridlon. 1985. Inhibition of rat uterine gland genesis by tamoxifen. Endocrinology 117:2238-2248.

Chen, D., E. Washbrook, N. Sarwar, G. J. Bates, P. E. Pace, V. Thirunuvakkarasu, J. Taylor, R. J. Epstein, F. V. Fuller-Pace, J. M. Egly, R. C. Coombes, and S. Ali. 2002. Phosphorylation of human estrogen receptor alpha at serine 118 by two distinct signal transduction pathways revealed by phosphorylation-specific antisera. Oncogene 21:4921-4931.

Connor, E. E., D. L. Wood, T. S. Sonstegard, A. F. da Mota, G. L. Bennett, J. L. Williams, and A. V. Capuco. 2005. Chromosomal mapping and quantitative analysis of estrogen-related receptor alpha-1, estrogen receptors alpha and beta and progesterone receptor in the bovine mammary gland. J. Endocrinol. 185:593-603.

Cooke, P. S., T. E. Spencer, F. F. Bartol, and K. Hayashi. 2013. Uterine glands: Development, function and experimental model systems. Mol. Hum. Reprod. 19:547-558.

Couse, J. F., D. Dixon, M. Yates, A. B. Moore, L. Ma, R. Maas, and K. S. Korach. 2001. Estrogen receptor-alpha knockout mice exhibit resistance to the developmental effects of neonatal diethylstilbestrol exposure on the female reproductive tract. Dev. Biol. 238:224-238.

Denton, R. R., N. J. Koszewski, and A. C. Notides. 1992. Estrogen receptor phosphorylation. Hormonal dependence and consequence on specific DNA binding. J. Biol. Chem. 267:7263-7268.

Fent, K., A. A. Weston, and D. Caminada. 2006. Ecotoxicology of human pharmaceuticals. Aquat. Toxicol. 76:122-159.

Ferguson, E. R., and B. S. Katzenellenbogen. 1977. A comparative study of antiestrogen action: temporal patterns of antagonism of estrogen stimulated uterine growth and effects on estrogen receptor levels. Endocrinology 100:1242-1251.

Fowler, P. A., M. Bellingham, K. D. Sinclair, N. P. Evans, P. Pocar, B. Fischer, K. Schaedlich, J. S. Schmidt, M. R. Amezaga, S. Bhattacharya, S. M. Rhind, and P. J. O'Shaughnessy. 2012. Impact of endocrine-disrupting compounds (EDCs) on female reproductive health. Mol. Cell. Endocrinol. 355:231-239. 
Frasor, J., D. H. Barnett, J. M. Danes, R. Hess, A. F. Parlow, and B. S. Katzenellenbogen. 2003. Response-specific and ligand dosedependent modulation of estrogen receptor (ER) alpha activity by ERbeta in the uterus. Endocrinology 144:3159-3166.

Frasor, J., F. Stossi, J. M. Danes, B. Komm, C. R. Lyttle, and B. S. Katzenellenbogen. 2004. Selective estrogen receptor modulators: Discrimination of agonistic versus antagonistic activities by gene expression profiling in breast cancer cells. Cancer Res. 64:15221533.

Giudice, L. C. 1994. Growth factors and growth modulators in human uterine endometrium: their potential relevance to reproductive medicine. Fertil. Steril. 61:1-17.

Gu, Y., W. S. Branham, D. M. Sheehan, P. J. Webb, C. L. Moland, and R. D. Streck. 1999. Tissue-specific expression of messenger ribonucleic acids for insulin-like growth factors and insulin-like growth factor-binding proteins during perinatal development of the rat uterus. Biol. Reprod. 60:1172-1182.

Hall, J. M., and D. P. McDonnell. 1999. The estrogen receptor betaisoform (ERbeta) of the human estrogen receptor modulates ERalpha transcriptional activity and is a key regulator of the cellular response to estrogens and antiestrogens. Endocrinology 140:55665578.

Hewitt, S. C., J. Collins, S. Grissom, B. Deroo, and K. S. Korach. 2005. Global uterine genomics in vivo: Microarray evaluation of the estrogen receptor alpha-growth factor cross-talk mechanism. Mol. Endocrinol. 19:657-668.

Hilton, M. J., and K. V. Thomas. 2003. Determination of selected human pharmaceutical compounds in effluent and surface water samples by high-performance liquid chromatography-electrospray tandem mass spectrometry. J. Chromatogr. A 1015:129-141.

Hoffmann, E. K. 2000. Intracellular signalling involved in volume regulatory decrease. Cell. Physiol. Biochem. 10:273-288.

Honaramooz, A., J. Aravindakshan, R. K. Chandolia, A. P. Beard, P. M. Bartlewski, R. A. Pierson, and N. C. Rawlings. 2004. Ultrasonographic evaluation of the pre-pubertal development of the reproductive tract in beef heifers. Anim. Reprod. Sci. 80:15-29.

Ignar-Trowbridge, D. M., M. Pimentel, M. G. Parker, J. A. McLachlan, and K. S. Korach. 1996. Peptide growth factor cross-talk with the estrogen receptor requires the A/B domain and occurs independently of protein kinase $\mathrm{C}$ or estradiol. Endocrinology 137:1735-1744.

Jager, N. G., H. Rosing, J. H. Schellens, S. C. Linn, and J. H. Beijnen. 2014. Tamoxifen dose and serum concentrations of tamoxifen and six of its metabolites in routine clinical outpatient care. Breast Cancer Res. Treat. 143:477-483.

Jefferson, W. N., J. F. Couse, E. Padilla-Banks, K. S. Korach, and R. R. Newbold. 2002. Neonatal exposure to genistein induces estrogen receptor (ER)alpha expression and multioocyte follicles in the maturing mouse ovary: Evidence for ERbeta-mediated and nonestrogenic actions. Biol. Reprod. 67:1285-1296.

Jefferson, W. N., E. Padilla-Banks, and R. R. Newbold. 2005. Adverse effects on female development and reproduction in CD-1 mice following neonatal exposure to the phytoestrogen genistein at environmentally relevant doses. Biol. Reprod. 73:798-806.

Kitajewski, J., and D. Sassoon. 2000. The emergence of molecular gynecology: Homeobox and Wnt genes in the female reproductive tract. BioEssays 22:902-910.

Kiyama, R., and Y. Wada-Kiyama. 2015. Estrogenic endocrine disruptors: Molecular mechanisms of action. Environ. Int. 83:11-40.

Klotz, D. M., S. C. Hewitt, K. S. Korach, and R. P. Diaugustine. 2000. Activation of a uterine insulin-like growth factor I signaling pathway by clinical and environmental estrogens: Requirement of estrogen receptor-alpha. Endocrinology 141:3430-3439.

Krege, J. H., J. B. Hodgin, J. F. Couse, E. Enmark, M. Warner, J. F. Mahler, M. Sar, K. S. Korach, J. A. Gustafsson, and O. Smithies. 1998. Generation and reproductive phenotypes of mice lacking estrogen receptor beta. Proc. Natl. Acad. Sci. USA 95:15677-15682.

Laemmli, U. K. 1970. Cleavage of structural proteins during the assembly of the head of bacteriophage T4. Nature 227:680-685.

Lanzino, M., C. Morelli, C. Garofalo, M. L. Panno, L. Mauro, S. Ando, and D. Sisci. 2008. Interaction between estrogen receptor alpha and insulin/IGF signaling in breast cancer. Curr. Cancer Drug Targets 8:597-610.

Leroy, J. L., S. D. Valckx, L. Jordaens, J. De Bie, K. L. Desmet, V. Van Hoeck, J. H. Britt, W. F. Marei, and P. E. Bols. 2015. Nutrition and maternal metabolic health in relation to oocyte and embryo quality: Critical views on what we learned from the dairy cow model. Reprod. Fertil. Dev. 27:693-703. http://dx.doi. org/10.1071/RD14363.

Lubahn, D. B., J. S. Moyer, T. S. Golding, J. F. Couse, K. S. Korach, and O. Smithies. 1993. Alteration of reproductive function but not prenatal sexual development after insertional disruption of the mouse estrogen receptor gene. Proc. Natl. Acad. Sci. USA 90:11162-11166.

McLachlan, J. A., S. L. Tilghman, M. E. Burow, and M. R. Bratton. 2012. Environmental signaling and reproduction: A comparative biological and chemical perspective. Mol. Cell. Endocrinol. 354:60-62.

Mericskay, M., J. Kitajewski, and D. Sassoon. 2004. Wnt5a is required for proper epithelial-mesenchymal interactions in the uterus. Development 131:2061-2072.

Milewicz, T., E. L. Gregoraszczuk, K. Sztefko, K. Augustowska, J. Krzysiek, and J. Rys. 2005. Lack of synergy between estrogen and progesterone on local IGF-I, IGFBP-3 and IGFBP-2 secretion by both hormone-dependent and hormone-independent breast cancer explants in vitro. Effect of tamoxifen and mifepristone (RU 486). Growth Horm. IGF Res. 15:140-147.

Miller, C., and D. A. Sassoon. 1998. Wnt-7a maintains appropriate uterine patterning during the development of the mouse female reproductive tract. Development 125:3201-3211.

Mueller, S. O., and K. S. Korach. 2001. Mechanisms of estrogen receptor-mediated agonistic and antagonistic effects. Pages 1-25 in The Handbook of Environmental Chemistry. Part L. Endocrine Disruptors, Part I, Vol. 3. M. Metzler, ed. Springer-Verlag, Berlin, Germany.

Mueller, S. O., S. Simon, K. Chae, M. Metzler, and K. S. Korach. 2004. Phytoestrogens and their human metabolites show distinct agonistic and antagonistic properties on estrogen receptor alpha (ERalpha) and ERbeta in human cells. Toxicol. Sci. 80:14-25.

Nayak, N. R., and L. C. Giudice. 2003. Comparative biology of the IGF system in endometrium, decidua, and placenta, and clinical implications for foetal growth and implantation disorders. Placenta $24: 281-296$

Polakis, P. 2000. Wnt signaling and cancer. Genes Dev. 14:1837-1851.

Pollak, M. N., H. T. Huynh, and S. P. Lefebvre. 1992. Tamoxifen reduces serum insulin-like growth factor I (IGF-I). Breast Cancer Res. Treat. 22:91-100.

Rhoads, M. L., J. P. Meyer, S. J. Kolath, W. R. Lamberson, and M. C. Lucy. 2008. Growth hormone receptor, insulin-like growth factor (IGF)-1, and IGF-binding protein-2 expression in the reproductive tissues of early postpartum dairy cows. J. Dairy Sci. 91:1802-1813.

Rivera, O. E., J. Varayoud, H. A. Rodriguez, M. Munoz-de-Toro, and E. H. Luque. 2011. Neonatal exposure to bisphenol A or diethylstilbestrol alters the ovarian follicular dynamics in the lamb. Reprod. Toxicol. 32:304-312.

Roberts, P. H., and K. V. Thomas. 2006. The occurrence of selected pharmaceuticals in wastewater effluent and surface waters of the lower Tyne catchment. Sci. Total Environ. 356:143-153.

Roshangar, L., J. S. Rad, and K. Afsordeh. 2010. Maternal tamoxifen treatment alters oocyte differentiation in the neonatal mice: Inhibition of oocyte development and decreased folliculogenesis. J. Obstet. Gynaecol. Res. 36:224-231.

Roy, R. N., A. H. Gerulath, A. Cecutti, and B. R. Bhavnani. 2000. Effect of tamoxifen treatment on the endometrial expression of human insulin-like growth factors and their receptor mRNAs. Mol. Cell. Endocrinol. 165:173-178.

Saji, S., E. V. Jensen, S. Nilsson, T. Rylander, M. Warner, and J. A. Gustafsson. 2000. Estrogen receptors alpha and beta in the rodent mammary gland. Proc. Natl. Acad. Sci. USA 97:337-342.

Sassoon, D. 1999. Wnt genes and endocrine disruption of the female reproductive tract: A genetic approach. Mol. Cell. Endocrinol. 158:1-5. 
Shupnik, M. A. 2004. Crosstalk between steroid receptors and the c-Src-receptor tyrosine kinase pathways: implications for cell proliferation. Oncogene 23:7979-7989.

Spencer, T. E., K. A. Dunlap, and J. Filant. 2012. Comparative developmental biology of the uterus: Insights into mechanisms and developmental disruption. Mol. Cell. Endocrinol. 354:34-53.

Spencer, T. E., K. Hayashi, J. Hu, and K. D. Carpenter. 2005. Comparative developmental biology of the mammalian uterus. Curr. Top. Dev. Biol. 68:85-122.

Swartz, C. D., C. A. Afshari, L. Yu, K. E. Hall, and D. Dixon. 2005. Estrogen-induced changes in IGF-I, Myb family and MAP kinase pathway genes in human uterine leiomyoma and normal uterine smooth muscle cell lines. Mol. Hum. Reprod. 11:441-450.

Taylor, K. M., C. Chen, C. A. Gray, F. W. Bazer, and T. E. Spencer. 2001. Expression of messenger ribonucleic acids for fibroblast growth factors 7 and 10, hepatocyte growth factor, and insulin-like growth factors and their receptors in the neonatal ovine uterus. Biol. Reprod. 64:1236-1246.

Taylor, K. M., C. A. Gray, M. M. Joyce, M. D. Stewart, F. W. Bazer, and T. E. Spencer. 2000. Neonatal ovine uterine development involves alterations in expression of receptors for estrogen, progesterone, and prolactin. Biol. Reprod. 63:1192-1204.

Thomas, K. V., and M. J. Hilton. 2004. The occurrence of selected human pharmaceutical compounds in UK estuaries. Mar. Pollut. Bull. 49:436-444.

Tucker, H. L., C. L. Parsons, S. Ellis, M. L. Rhoads, and R. M. Akers. 2016. Tamoxifen impairs prepubertal mammary development and alters expression of estrogen receptor alpha (ESR1) and progesterone receptors (PGR). Domest. Anim. Endocrinol. 54:95-105.

Vainio, S., M. Heikkila, A. Kispert, N. Chin, and A. P. McMahon. 1999. Female development in mammals is regulated by Wnt-4 signalling. Nature 397:405-409.

Vallet, J. L., R. K. Christenson, F. F. Bartol, and A. A. Wiley. 1995. Effect of treatment with retinyl palmitate, progesterone, oestradiol and tamoxifen on secretion of a protein similar to retinol-binding protein during uterine gland development in neonatal pigs. J. Reprod. Fertil. 103:189-197.

van der Horst, P. H., Y. Wang, M. van der Zee, C. W. Burger, and L. J. Blok. 2012. Interaction between sex hormones and WNT/betacatenin signal transduction in endometrial physiology and disease. Mol. Cell. Endocrinol. 358:176-184.

Velayudhan, B. T., B. P. Huderson, S. E. Ellis, C. L. Parsons, R. C. Hovey, A. R. Rowson, and R. M. Akers. 2015. Ovariectomy in young prepubertal dairy heifers causes complete suppression of mammary progesterone receptors. Domest. Anim. Endocrinol. $51: 8-18$.

Walsh, S. W., E. J. Williams, and A. C. Evans. 2011. A review of the causes of poor fertility in high milk producing dairy cows. Anim. Reprod. Sci. 123:127-138.

Webb, P., P. Nguyen, and P. J. Kushner. 2003. Differential SERM effects on corepressor binding dictate ERalpha activity in vivo. J. Biol. Chem. 278:6912-6920.

Wiley, A. A., F. F. Bartol, and D. H. Barron. 1987. Histogenesis of the ovine uterus. J. Anim. Sci. 64:1262-1269.

Wu, H., Y. Chen, J. Liang, B. Shi, G. Wu, Y. Zhang, D. Wang, R. Li, X. Yi, H. Zhang, L. Sun, and Y. Shang. 2005. Hypomethylationlinked activation of PAX2 mediates tamoxifen-stimulated endometrial carcinogenesis. Nature 438:981-987.

Yamaguchi, T. P., A. Bradley, A. P. McMahon, and S. Jones. 1999. A Wnt5a pathway underlies outgrowth of multiple structures in the vertebrate embryo. Development 126:1211-1223.

Yu, L., A. B. Moore, L. Castro, X. Gao, H. L. Huynh, M. Klippel, N. D. Flagler, Y. Lu, G. E. Kissling, and D. Dixon. 2012. Estrogen regulates MAPK-related genes through genomic and nongenomic interactions between IGF-I receptor tyrosine kinase and estrogen receptor-alpha signaling pathways in human uterine leiomyoma cells. J. Signal Transduct. 2012:204236. 